\title{
Anticoagulation in hyperosmolar hyperglycaemic state: a case report and review of the literature
}

\author{
SING YEE SIM, ${ }^{1}$ AMY MORRISON, ${ }^{1}$ ROBERT GREGORY, ${ }^{2}$ MARIE-FRANCE KONG ${ }^{2}$
}

Key words: type 2 diabetes, hyperosmolar hyperglycaemic state, case report, anticoagulation, venous thromboembolism, low molecular weight heparin

\section{Introduction}

Hyperosmolar hyperglycaemic state (HHS) is one of two serious metabolic derangements that occur in people with diabetes mellitus. The first cases of HHS were described by von Frerichs and Dreschfeld in the 1880s with an 'unusual diabetic coma'. It is a serious, life-threatening, but fortunately rare emergency that, although less common than its counterpart, diabetic ketoacidosis (DKA), has around a 10 times higher mortality rate, up to 15-20\%. ${ }^{1}$ HHS accounts for around $1 \%$ of hospital admissions in people with diabetes, typically in the elderly. Increasing prevalence of obesity has additionally increased the incidence of HHS in the paediatric population. Prognosis is worse when associated with increasing comorbidities, age and significant electrolyte abnormalities. ${ }^{2}$ It is well known that diabetes can affect the clotting pathway, resulting in endothelial dysfunction, eventually enhancing the activation of procoagulant factors, predisposing towards thrombosis. This process is further amplified in both hyperosmolarity and DKA. ${ }^{3}$

Several case reports highlight the significant mortality and morbidity that can be associated with venous thromboembolism (VTE) and its complications in people with hyperosmolarity including fatality from massive pulmonary embolism. ${ }^{1}$ Patients having major orthopaedic surgery tend to receive extended VTE prophylaxis and demonstrate significant reduction in VTE with this therapy. Given the paucity of evidence for prophylactic versus therapeutic anticoagulation in HHS, we looked at the evidence surrounding orthopaedic surgery where there has been considerable research.

Specialist Registrar in Diabetes \& Endocrinology, University Hospitals of Leicester NHS Trust, Leicester, UK

2 Consultant Diabetes \& Endocrinology, University Hospitals of Leicester NHS Trust, Department of Diabetes, Leicester General Hospital,

Gwendolen Road, Leicester, UK

Address for correspondence: Dr Sing Yee Sim

Specialist Registrar in Diabetes \& Endocrinology, University of Leicester NHS Trust, Leicester, LE1 5WW, UK

E-mail: sing.y.sim@uhl-tr.nhs.uk

Br J Diabetes 2021;21:250-254

https://doi.org/10.15277/bjd.2021.313
Direct oral anticoagulants are now being used for VTE prophylaxis in orthopaedic patients and may have a role in acutely unwell medical patients with a low risk of bleeding. ${ }^{4}$

The evidence regarding the potential benefit of prolonged anticoagulation in HHS remains unclear. ${ }^{5}$ We performed a literature review to look at the evidence.

\section{Case report}

Patient information

A 63-year-old man with diet-controlled type 2 diabetes mellitus for 2 years, with body mass index $28.3 \mathrm{~kg} / \mathrm{m}^{2}$, was admitted with a two-week history of lethargy and a one-month history of severe osmotic symptoms (polyuria and polydipsia). He had recently been treated for a urinary tract infection. He reported weight loss of $3 \mathrm{~kg}$ in the week preceding admission. Three weeks prior to presentation he had returned from the USA on a long-haul flight. He had a 24-hour history of confusion, with no associated chest pain, shortness of breath or palpitations. There was no history of alcohol consumption or smoking. There was a family history of type 2 diabetes mellitus.

\section{Clinical findings}

On admission he had a Glasgow Coma Scale of 14/15. He was tachycardic with pulse rate $100 \mathrm{bpm}$, but was otherwise haemodynamically stable although clinically dehydrated. A venous blood gas highlighted metabolic acidosis ( $\mathrm{pH}$ 7.2), blood ketones were $3.3 \mathrm{mmol} / \mathrm{L}$ and additional laboratory investigations indicated acute renal impairment with hypernatraemia $\left(\mathrm{Na}^{+} 155 \mathrm{mmol} / \mathrm{L}, \mathrm{K}^{+}\right.$ $4.9 \mathrm{mmol} / \mathrm{L}$, urea $39.8 \mathrm{mmol} / \mathrm{L}$, creatinine $460 \mu \mathrm{mol} / \mathrm{L}$, estimated glomerular filtration rate (eGFR) $12 \mathrm{~mL} / \mathrm{min}$ and glucose $70 \mathrm{mmol} / \mathrm{L}$, normal full blood count). His $\mathrm{HbA}_{1 \mathrm{c}}$ was $6.8 \%(51 \mathrm{mmol} / \mathrm{mol}) 6$ months previously. Calculated serum osmolality was $429.6 \mathrm{mOsm} /$ kg (normal range 278-305).

\section{Diagnostic assessment}

The working diagnosis on admission was a combination of HHS/DKA with infection (likely urinary tract infection) as a precipitant, acute kidney injury stage 3 and delirium presumed secondary to these conditions.

\section{Therapeutic intervention}

He was started on the trust's HHS treatment protocol which is similar to the JBDS guidance. He was also commenced on 
Table 1 Timeline: serum sodium, platelets, haemoglobin, white cell count and creatinine results over course of admission

\begin{tabular}{|c|c|c|c|c|c|}
\hline Date & $\begin{array}{l}\mathrm{Na}+ \\
(\mathrm{mmol} / \mathrm{L})\end{array}$ & $\begin{array}{l}\text { Platelets } \\
\left(\times 10^{9} / \mathrm{L}\right)\end{array}$ & $\begin{array}{l}\text { Haemoglobin } \\
\text { (g/L) }\end{array}$ & $\begin{array}{l}\text { WCC } \\
\left(\times 10^{9} / \mathrm{L}\right)\end{array}$ & $\begin{array}{l}\text { Creatinine } \\
(\mu \mathrm{mol} / \mathrm{L})\end{array}$ \\
\hline $25 / 03 / 16$ & 155,170 & 123,107 & 166,155 & $7.8,8.6$ & 460,345 \\
\hline 26/03/16 & $168,161,164$ & $58,45,38$ & $142,128,127$ & $10.1,8.5,8.9$ & $272,269,245$ \\
\hline $27 / 03 / 16$ & 164,158 & 28,28 & 121,115 & $7.1,6.9$ & 173,159 \\
\hline 28/03/16 & 161,154 & 30,55 & 115,121 & $5.8,5.6$ & 134,120 \\
\hline 29/03/16 & 149 & 35 & 128 & 4.5 & 98 \\
\hline $30 / 03 / 16$ & 150,146 & 61,84 & 115,114 & $4.7,4.7$ & 105,91 \\
\hline $31 / 03 / 16$ & 146 & 84 & 119 & 5 & 90 \\
\hline $02 / 04 / 16$ & 144 & 165 & 104 & 4.9 & 96 \\
\hline
\end{tabular}

prophylactic low molecular weight heparin (LMWH; dalteparin) which was accurately dosed according to weight and eGFR and stopped after 3 days as his platelet count dropped (see Table 1) after discussion with the haematology team. Although he had recently returned from a long-haul flight, the admitting team did not feel VTE was likely as he did not have clinical features suggestive of thromboembolism and had not had surgery in the previous 4 weeks. The focus was on the treatment of sepsis and HHS/DKA. He was treated with intravenous antibiotics in a dose appropriate for his renal function. His biochemical parameters, notably renal function, improved with fluid resuscitation (Table 1).

On day 2 of admission he was noted to have dynamic ECG changes with raised troponin-I (2,673 ng/L peaking at 3,820 ng/L [normal <40 ng/L]). He was initially treated for a non-ST elevation myocardial infarction. On advice of the cardiologist and the haematologist, he was started on aspirin without clopidogrel and continued on 5,000 units of dalteparin instead of enoxaparin. On day 5 of admission he became acutely hypoxic with shortness of breath whilst walking to the toilet and a CT pulmonary angiogram (CTPA) was performed which showed extensive pulmonary embolism (saddle embolus with extension into the segmental pulmonary arteries bilaterally) without right ventricular strain. The CTPA also revealed bilateral basal pneumonia. His capillary blood glucose was $15 \mathrm{mmol} / \mathrm{L}$ and his serum sodium was $149 \mathrm{mmol} / \mathrm{L}$ on the day of his CTPA. Anticoagulation treatment was challenging in view of his thrombocytopenia. He was not thrombolysed. On the advice of the haematology team he was given a platelet transfusion, aiming for a platelet count of $>50 \times 10^{9} / \mathrm{L}$. He was then commenced on a treatment dose of dalteparin (15,000 units) and later switched to warfarin under the guidance of the haematology team. The drop in platelet count was felt to be due to consumption coagulopathy. The plan was to give warfarin for 6 months and to be reviewed by the haematology team.

He had a coronary angiogram as an inpatient which showed unobstructed coronaries. An echocardiogram showed mild to moderate concentric left ventricular hypertrophy, no significant left ventricular outflow tract obstruction, normal systolic function and no significant valvular abnormalities. The raised troponin-I was attributed to subendocardial ischaemia in the right ventricle which is seen in acute pulmonary embolism.

\section{Follow-up and outcome}

He was discharged home taking Humulin I insulin twice a day. When reviewed in the outpatient clinic two months later, his insulin was stopped and treatment switched to metformin alone.

\section{Discussion}

HHS is associated with a hypercoagulable state. The onset of HHS is usually over days with significant metabolic derangements, dehydration and hyperglycaemia. This occurs due to increased levels of counter-regulatory hormones such as glucagon, catecholamines, cortisol and growth hormone from a relatively insulin-deficient state. Hyperglycaemia develops due to increased glycogenolysis, reduction in glucose utilisation and gluconeogenesis. In contrast to DKA, in HHS the insulin level is adequate to prevent lipolysis and ketogenesis, but not to stimulate glucose utilisation. ${ }^{6}$ This leads to an osmotic diuresis, resulting in intracellular dehydration and a hyperosmolar state. In HHS it can lead to significant intravascular dehydration $(6-13 \mathrm{~L}$ in a person weighing $60 \mathrm{~kg}){ }^{1,7}$ There is also an increase in pro-inflammatory cytokines creating a pro-thrombotic environment. ${ }^{7}$ This can lead to thromboembolic events, cerebrovascular accident, disseminated intravascular coagulopathy, myocardial infarction and peripheral or central vascular occlusion. Chaudhuri and Umpierrez noted normalisation of circulating pro-inflammatory cytokines upon reduction of blood glucose concentration. ${ }^{8}$ The large increase in reactive oxygen species leads to damage of lipids and proteins at the cellular level.

Common precipitants include sepsis (up to 60\%), poor medication adherence (21\%), undiagnosed diabetes (11\%) and medical illness such as stroke or myocardial infarction that causes release of counter-regulatory hormones. ${ }^{7,9}$

\section{Methodology and review}

We carried out a literature search using our own Clinical Information Search System (CISS) through Medline, Embase, Pubmed, Uptodate and BMJ best practice using the terms "Hyperosmolar or HHS" in association with "DVT or PE". We found 19 papers in total. After excluding six paediatric papers, one paper focusing on DKA and another seven papers based on their title and content, we were left with five papers describing some form of association between HHS, thromboembolism and clinical approach (Table 2 and Figure 1).

\section{HHS and VTE management}

Diabetes alone is a risk factor for VTE in comparison with the nondiabetic population. A retrospective study of 302 adult patients (56 patients with diabetes and 246 without) identified an annual VTE incidence rate among people with diabetes of 432 per 100,000 compared with 78 per 100,000 in those without diabetes. ${ }^{10}$ Patients with diabetes have a 1.7-fold increased risk of VTE compared with those without diabetes. After adjusting for age, there remains a two-fold risk increase in patients with diabetes. 
Table 2 Summary of articles reviewed

\begin{tabular}{|c|c|c|c|c|}
\hline Author & Type of article & Cohort/subject & Learning points & Limitations \\
\hline Park et al, $2006^{11}$ & Case report & $\begin{array}{l}\text { HHS patient complicated by extensive upper } \\
\text { extremity venous thrombosis }\end{array}$ & $\begin{array}{l}\text { Current experiences support the safety and } \\
\text { efficacy of catheter-directed thrombolysis. } \\
\text { There is inadequate clinical evidence for full } \\
\text { anticoagulation. }\end{array}$ & Case report on one patient \\
\hline Hamblin et al, $1989^{12}$ & Journal article & $\begin{array}{l}\text { Hyperglycaemic complications of diabetes in } \\
\text { people with diabetic ketoacidosis and HHS }\end{array}$ & $\begin{array}{l}\text { The mortality rate was } 14.6 \% \text { ( } 12 \text { deaths) for } \\
82 \text { episodes of HHS. Six cases of mesenteric } \\
\text { and iliac thromboses, eight cases of myocardial } \\
\text { infarction and two cases of cerebral haemorrhage } \\
\text { were identified }\end{array}$ & $\begin{array}{l}\text { Therapeutic anticoagulation not } \\
\text { given to patients prior to diagnosis } \\
\text { of VTE }\end{array}$ \\
\hline Keenan et al, $2007^{13}$ & Journal article & Risk of VTE in patients hospitalised for HHS & $\begin{array}{l}32(1.2 \%) \text { of } 2,859 \text { people with HHS developed } \\
\text { VTE in hospital. HHS (HR=3.0) compared to } \\
\text { DKA (HR=1.2) }\end{array}$ & $\begin{array}{l}\text { Recommended extended duration } \\
\text { of VTE prophylaxis in HHS patients, } \\
\text { but duration unclear }\end{array}$ \\
\hline Sinson et al, 2016 & Case report & $\begin{array}{l}\text { Renal vein thrombosis developed in an } \\
\text { HHS patient }\end{array}$ & $\begin{array}{l}\text { Poorly controlled type } 2 \text { diabetes is associated } \\
\text { with high levels of plasminogen activator } \\
\text { inhibitor-1 resulting in reduced fibrinolysis }\end{array}$ & $\begin{array}{l}\text { Case report of one patient and no } \\
\text { recommendations given for } \\
\text { duration of VTE prophylaxis }\end{array}$ \\
\hline Wordsworth et al, $2014^{19}$ & Case report & $\begin{array}{l}\text { Massive pulmonary embolism associated } \\
\text { with HHS }\end{array}$ & & $\begin{array}{l}\text { Case report of one patient, } \\
\text { prophylaxis anticoagulation given }\end{array}$ \\
\hline
\end{tabular}

Figure 1. Methodology and review

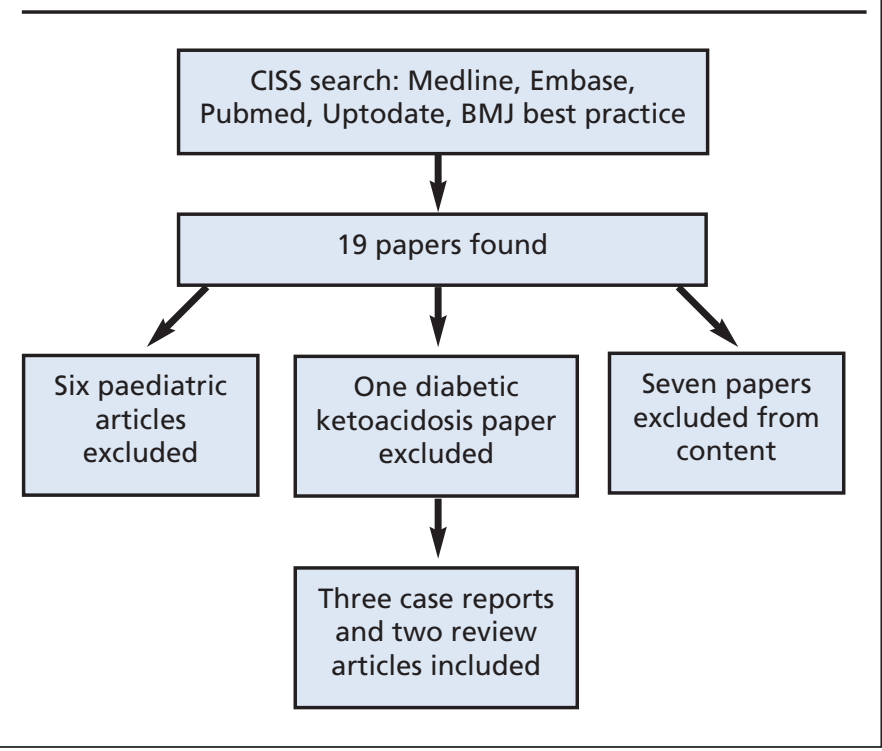

Park et $a^{11}$ reported a case of extensive venous thrombosis of the upper extremity 30 hours after placement of a subclavian venous catheter in a patient with HHS. The patient was treated with early catheter-directed thrombolysis followed by anticoagulation. Full anticoagulation was not recommended due to bleeding risk.

Hamblin et a/ $/^{12}$ reported a mortality rate of $14.6 \%$ in 82 patients diagnosed with HHS. They identified six cases of mesenteric and iliac thromboses, eight cases of myocardial infarction and two cases of cerebral haemorrhage in these patients.

Keenan et $a^{13}$ identified an incidence of VTE in patients with HHS of $1.7 \% ; 71 \%$ were diagnosed during hospital stay and a further 29\% were diagnosed within 3 months following hospital discharge. In comparison, patients undergoing total hip replacement had a VTE incidence of around $2.8 \%$, suggesting that patients with HHS are at very high risk of VTE. Furthermore, the incidence of VTE in those with HHS - even after adjusting for age, ethnicity, gender and recent hospitalisation - was found to be higher than that of people with uncomplicated diabetes and DKA. This work suggests that the increased thrombotic risk in patients with HHS can be attributed to the more profound hyperosmolarity and hyperglycaemia. Keenan et al have suggested extended duration of VTE prophylaxis, especially in very highrisk groups. The VTE risk is comparable to patients with sepsis and acute connective tissue disease..$^{13}$

Sinson et al $^{14}$ reported a case of acute pyelonephritis with renal vein and inferior vena cava thrombosis. This patient was initially managed according to the HHS protocol and given prophylactic anticoagulation. Subsequently, the patient developed renal vein thrombosis and pulmonary embolism. There is an associated increase in plasminogen activator inhibitor-1 inhibiting fibrinolysis and increasing the thrombosis risk in patients with poorly controlled type 2 diabetes. Once again there were no clear recommendations for anticoagulation.

\section{Heparin and bleeding prediction scores}

It is still debatable whether all patients with HHS should be given treatment dose anticoagulation. HHS tends to occur in the older population. The risk of VTE increases significantly with age, particularly in those aged $\geq 75$ years, with an odds ratio of 1.5 for every 10 years of increase in age. Campbell et a/ ${ }^{15}$ found that ageing is associated with increased heparin levels after standard heparin doses and therefore lower heparin dose requirements. A decline in renal function, especially in patients with creatinine clearance $<30 \mathrm{~mL} / \mathrm{min}$, genetic polymorphisms and drug inter- 


\section{Key messages}

- HHS is a hypercoagulable state associated with signifi-cant risk of venous thromboembolism and high mortality

- Clinicians need to assess each patient's risks independently. High risk patients with low bleeding risk should be considered for therapeutic anticoagulation throughout their hospital stay

- Careful monitoring of the clinical status and discussion involving the haematology team if needed will help decide the optimal anticoagulation therapy

action particularly affecting cytochrome P450 activity, can all have an impact on thrombotic versus bleeding risk. Elderly patients on vitamin $\mathrm{K}$ antagonists (warfarin) for metallic heart valve or previous thromboembolic events can have significant variability in their INR level due to poor dietary vitamin $\mathrm{K}$ intake and poor absorption from altered intestinal flora. ${ }^{15}$

The use of bleeding prediction scores can help guide management in patients with thromboembolic events. Klok et a/16 reviewed the performance of the VTE-BLEED score (consisting of six objective clinical variables) and found the VTE-BLEED score to be superior to other bleeding scores in predicting bleeding risk. It is mainly used as a tool in patients with a previous diagnosis of VTE, on anticoagulation to predict bleeding risk. It also helps to guide clinicians in decision making regarding extension of anticoagulation, depending on a patient's risk of long-term VTE recurrence. They found therapeutic anticoagulation to be safe in low-risk people, but in high-risk people more studies are required. This tool is awaiting further prospective validation before being incorporated into clinical practice. ${ }^{16} \mathrm{It}$ is unclear whether patients with HHS were included in this study.

With the COVID-19 pandemic there have been numerous studies looking at therapeutic anticoagulation. The ATTAC/ACTIV-4a and REMAP-CAP multiplatform randomised controlled trial suggested giving a therapeutic dose of thromboprophylaxis to hospitalised non-intensive care patients with COVID-19. The dose is weight-based unless the creatinine clearance is $<30 \mathrm{~mL} / \mathrm{min}$, for which heparin assay needs to be checked on day 3 . However, the evidence surrounding therapeutic anticoagulation in HHS remains limited. ${ }^{17}$

A study in Canada evaluated the efficacy of extending VTE prophylaxis in acutely unwell medical patients. Using extended duration of enoxaparin reduced VTE by $1.5 \%$ but increased major bleeding events by $0.5 \%$. This was only beneficial in the cohort of people who were aged $>75$ years and female. ${ }^{18}$ There is a need for a clearer evidence-based risk stratification tool to guide clinicians about duration and dosing of VTE prophylaxis.

\section{Conclusion}

This case highlights the increased and potentially fatal thrombo- sis risk associated with hyperosmolarity and HHS, highlighting the difficulties in the production of guidelines for prophylactic versus treatment dose anticoagulation in the absence of a strong evidence base.

The current JBDS guidelines recommend prophylactic LMWH for the full duration of hospital stay in people with HHS. However, there remains limited evidence on using treatment anticoagulation in people with HHS who are at high risk of thromboembolism. Most guidelines available are based on case reports and observational studies alone. Currently, an extended course of LMWH is only recommended for people at high risk. A therapeutic dose of LMWH is not currently recommended due to associated bleeding risks, unless there is evidence of acute coronary syndrome or thrombosis.

Clinicians should assess each patient's risks independently. If a person is deemed to be at high risk of thrombosis, full dose anticoagulation should be given. We have been agonising about the clinical management decision regarding anticoagulation in HHS for far too long and there is an urgent need for a randomised controlled trial.

\section{Conflict of interest All authors have none to declare. Funding None.}

\section{References}

1. Joint British Diabetes Societies Inpatient Care Group. The management of the hyperosmolar hyperglycaemic state (HHS) in adults with diabetes. August 2012. https://diabetes-resources-production.s3-eu-west-1.amazonaws.com/diabetes-storage/migration/pdf/JBDS-IP-HHS-Adults.pdf

2. Kitabchi AE, Umpierrez GE, Miles JM, Fisher JN. Hyperglycemic crises in adult patients with diabetes. Diabetes Care 2009;32:1335-43. https://doi.org/10.2337/dc09-9032

3. Shujaat A, Shapiro JM. Massive pulmonary embolism in diabetic ketoacidosis and non-ketotic hyperosmolar state: case series and review of the literature. Clin Intensive Care 2004;15(2-3):73-7. https://doi.org/10.3109/ 09563070410001711771

4. Goh EL, Gurung KP, Ma S, et al. Direct oral anticoagulants in the prevention of venous thromboembolism following surgery for hip fracture in older adults: a population based cohort study. Geriatr Orthop Surg Rehabil 2020; 11:2151459319897520. https://doi.org/10.1177/2151459319897520

5. Turpie AGG. Extended duration of thromboprophylaxis in acutely ill medical patients, optimising therapy? J Thromb Haemost 2007;5(1):511. https://doi.org/10.1111/j.1538-7836.2006.02268.x

6. Gosmanov AR, Gosmanova EO, Kitabchi AE. Hyperglycemic crises: diabetic ketoacidosis and hyperglycemic hyperosmolar state. [Updated 9 May 2021]. In: Feingold KR, Anawalt B, Boyce A, et al, editors. Endotext [Internet]. South Dartmouth, Massachusetts: MDText.com, 2000. Available from: https://www.ncbi.nlm.nih.gov/books/NBK279052/

7. Pasquel FJ, Umpierrez GE. Hyperosmolar hyperglycaemic state: a historic review of the clinical presentation, diagnosis, and treatment. Diabetes Care 2014;37(11):3124-31. https://doi.org/10.2337/dc14-0984

8. Chaudhuri A, Umpierrez GE. Oxidative stress and inflammation in hyperglycemic crises and resolution with insulin: implications for the acute and chronic complications of hyperglycemia. J Diabetes Complications 2012;26(4):257-8. https://doi.org/10.1016/j.jdiacomp.2012.04.016.

9. Chu CH, Lee JK, Lam HC, Lu CC. Prognostic factors of hyperglycemic hyperosmolar nonketotic state. Chang Gung Med J 2001;24(6):345-51.

10. Petrauskiene $\mathrm{V}$, Falk M, Waernbaum I, et al. The risk of venous thromboembolism is markedly elevated in patients with diabetes. Diabetologia 2005;48:1017-21. https://doi.org/10.1007/s00125-005-1715-5

11. Park J, Kim DJ, Kim HY, et al. Extensive venous thrombosis of the upper extremity in a diabetic patient with hyperosmolar hyperglycemic state. Korean J Intern Med 2006;21(4):244-7. https://doi.org/10.3904/ kjim.2006.21.4.244 


\section{CASE REPORT}

12. Hamblin PS, Topliss DJ, Chosich N, et al. Deaths associated with diabetic ketoacidosis and hyperosmolar coma 1973-1988. Med J Aust 1989; 151(8): 439, 441-2, 444. https://doi.org/10.5694/j.1326-5377.1989.tb101253.x

13. Keenan $\mathrm{CR}$, Murin S, White RH. High risk for venous thromboembolism in diabetics with hyperosmolar state: comparison with other acute medical illnesses. J Thromb Haemost 2007;5(6):1185-90. https://doi.org/ 10.1111/j.1538-7836.2007.02553.x

14. Sinson N, van Veen JJ, Brown PL, Creagh F. Acute pyelonephritis with renal vein and inferior vena cava thrombosis and pulmonary emboli in poorly controlled type 2 diabetes and HHS. Pract Diabetes 2016; 33(5):167-9. https://doi.org/10.1002/pdi.2029

15. Campbell NR, Hull RD, Brant R, et al. Aging and heparin-related bleeding. Arch Intern Med 1996:156(8):857-60.

16. Klok FA, Hösel $V$, Clemens $A$, et al. Prediction of bleeding events in patients with venous thromboembolism on stable anticoagulation treatment. Eur Respir J 2016;48:1369-76. https://doi.org/10.1183/ 13993003.00280-2016

17. ATTACC, ACTIV-4a and REMAP-CAP multiplatform RCT. Results of interim analysis. January 2021. https://nhlbi-connects.org/documents/ mpRCT\%20Interim\%20Presentation.pdf (Accessed 5 March 2021).

18. Hull RD, Schellong SM, Tapson VF, et al. Extended-duration venous thromboembolism prophylaxis in acutely ill medical patients with recently reduced mobility: a randomized trial. Ann Intern Med 2010;153(1):8-18. https://doi.org/10.7326/0003-4819-153-1-201007060-00004

19. Wordsworth G, Robinson A, Ward A, Atkin M. HHS - full or prophylactic anticoagulation? Br J Diabetes 2014;14(2). https://doi.org/10.15277/ bjdvd.2014.011 